\title{
INJÚRIAS MECÂNICAS E SEUS EFEITOS EM PÊSSEGOS 'AURORA-1’’
}

\author{
GIORGIA FERNANDA KASAT ${ }^{2}$,BEN-HUR MATTIUZ ${ }^{3}$, FLÁVIA OKUSHIRO OGASSAVARA ${ }^{4}$, \\ MATHEUS SARAIVA BIANCO ${ }^{4}$, CRISTIANE MARIA ASCARI MORGADO ${ }^{4}$, LUIS CARLOS CUNHA JUNIOR $^{5}$
}

RESUMO - O objetivo deste trabalho foi avaliar os efeitos das injúrias mecânicas por corte, compressão e impacto na qualidade póscolheita de pêssegos 'Aurora-1'. Na injúria por impacto, os pêssegos foram deixados cair duas vezes de uma altura de 1,20 m. Por compressão, os frutos foram colocados sob um bloco exercendo um peso constante de $3 \mathrm{~kg}$ por 10 minutos. Para a injúria por corte, promoveram-se três incisões longitudinalmente. Manteve-se, ainda, um lote de pêssegos intactos, correspondente ao controle. Após esses tratamentos, os frutos foram armazenados a $10 \pm 1,5^{\circ} \mathrm{C}$ e $85 \pm 2 \%$ UR por 8 dias. Avaliaram-se o teor de sólidos solúveis (SS), de acidez titulável (AT) e a relação SS/AT, a perda de massa fresca, a aparência, a coloração, a firmeza e o conteúdo de carboidratos solúveis. As injúrias mecânicas promoveram marcas nos pêssegos 'Aurora-1', afetando a aparência dos mesmos, que obtiveram nota ruim a partir do sexto dia de armazenamento. Esses pêssegos, quando submetidos à injúria de impacto, apresentaram maior perda de massa fresca que os do controle, da compressão e do corte. As áreas lesionadas apresentaram-se mais escurecidas, menos amareladas, com menor cromaticidade e menos firmes que as áreas dos frutos não-submetidas às injúrias. Esse efeito deletério também foi verificado quando os frutos eram submetidos à injúria por Impacto, quando comparado com os demais tratamentos. As injúrias mecânicas promoveram um amadurecimento mais rápido dos frutos, verificado pelos maiores valores da relação SS/AT.

Termos para Indexação: Prunus persica, pós-colheita, dano mecânico.

\section{EFFECT OF MECHANICAL INJURIES ON ‘AURORA-1’ PEACHES}

\begin{abstract}
This work aimed to evaluate the effect of mechanical injuries, impact, compression and cut on the postharvest quality of peaches cv. Aurora-1. Impact injury was obtained dropping fruit, twice, from a height of $1.20 \mathrm{~m}$. Compression injury was performed with the fruit submitted to weight $(3 \mathrm{~kg})$ for 10 minutes. Cut injury was obtained cutting fruits, three times, in the longitudinal direction. after these treatments the injured fruit and the control (not damage fruit) were stored to $10 \pm 1.5^{\circ} \mathrm{C}$ and $85 \pm 2 \% \mathrm{RH}$ for 8 days. The loss of fresh mass, appearance, color and contents of soluble solids (SS), titratable acidity (TA), soluble sugars, $\mathrm{pH}$ and firmness were evaluated. Mechanical injuries promoted marks in peaches 'Aurora-1', affecting the appearance that obtained a low score at the sixth day of storage. 'Aurora-1' peaches submitted to impact had greater loss of fresh mass than control, compression and cut. The injured area was darker and colorless than intact areas. This deleterious effect also was verified when the fruit were submitted to impact, when compared with the other treatments. The chemical composition was not affected by the injuries. During the storage there was an increase in SS content and soluble sugars and reduction in TA, resulting in better ratio SS:TA.
\end{abstract}

Index Terms: Prunus persica, postharvest, mechanical damages.

\section{INTRODUÇÃO}

A produção brasileira de pêssegos no ano de 2003 foi de 220.364 toneladas, sendo que o Estado de São Paulo $\left(2^{\circ}\right.$ maior produtor nacional) contribuiu com 47.387 toneladas deste total, cujo maior destino é o consumo in natura (AGRIANUAL, 2006).

A cultivar Aurora-1 é uma planta vigorosa, de excepcional produtividade e pouco exigente em frio. A colheita de seus frutos inicia-se em meados de outubro e estende-se até o final de novembro. Segundo Ojima et al. (1992), os frutos têm peso médio entre 90 e $110 \mathrm{~g}$, formato oblongo, casca com fundo amarelado e matiz vermelho-intensa, caroço pequeno e preso, polpa firme e amarelada com auréola tênue ao redor do caroço, sabor acentuadamente doce, baixa acidez (pH 4,6) e teor de açúcares em torno de $14^{\circ}$ Brix.
O pêssego é uma fruta muito apreciada devido a sua beleza, aroma e sabor característico. Segundo Pereira et al. (2002), o consumo de pêssegos é da ordem de $700 \mathrm{a} 800 \mathrm{~g}$ por habitante ao ano, com perspectivas para absorção no mercado brasileiro de cerca de 100 mil toneladas de pêssegos frescos por ano. Segundo Chitarra \& Carvalho (1985), o pêssego é um fruto climatérico, rico em carboidratos, com predominância da sacarose sobre os açúcares redutores glicose e frutose, sendo que o aumento mais rápido na concentração desse açúcar ocorre nas últimas semanas de maturação. Com o amadurecimento do fruto, ocorre a diminuição da acidez e o aumento nos valores de $\mathrm{pH}$.

As perdas na pós-colheita atingem montantes expressivos, e os índices estimados podem alcançar cifras da ordem de $30 \%$ ou mais da produção. Essas perdas estão especialmente relacionadas com produtos altamente perecíveis,

\footnotetext{
${ }^{1}$ (Trabalho 149-06). Recebido em : 03-10-2006. Aceito para publicação em : 08-05-2006.

${ }^{2} \mathrm{Eng}^{\mathrm{a}}$ Agr ${ }^{\mathrm{a}}$ formada pela Universidade Estadual Paulista, UNESP-FCAV. E-mail: giorgia.kasat@citrovita.com.br

${ }^{3}$ Eng. Agr., Dr., Professor do Departamento de Tecnologia da Universidade Estadual Paulista. UNESP-FCAV, Campus de Jaboticabal. Via de Acesso Prof. Paulo Donato Castellane, s/n. CEP: 14.884-900. Jaboticabal-SP. E-mail: benhur@fcav.unesp.br

${ }^{4}$ Alunos do Curso de Graduação em Agronomia da Universidade Estadual Paulista, UNESP-FCAV. flaviaokog@hotmail.com; matheus_bianco@hotmail.com; cristianeascari@hotmail.com

${ }^{5}$ Eng. Agr., aluno do Curso de Pós-Graduação em Produção Vegetal da UNESP-FCAV. E-mail: luis.cunha@posgrad.fcav.unesp.br
} 
como as frutas e hortaliças, que, juntamente com as raízes e bulbos, representam em torno de $25 \%$ das principais safras de alimentos produzidos nos países em desenvolvimento. Dentre as principais causas, pode-se citar o descuido no manuseio dos produtos (Chitarra \& Chitarra, 2005).

As lesões mecânicas, durante o manejo na colheita e póscolheita, são responsáveis por perdas significativas durante a distribuição e a comercialização dos vegetais. Essas injúrias afetam diretamente o fruto, causando danos irreparáveis, que desvalorizam comercialmente o produto e reduzem sua vida útil. Frutos murchos, amassados, sem a cor característica e com aparência desagradável sobram nas prateleiras dos supermercados.

As injúrias mecânicas, devido a impactos, compressões, cortes e rachaduras, são deformações plásticas, rupturas superficiais e destruição dos tecidos vegetais e/ou alterações fisiológicas, químicas e bioquímicas, que promovem alterações fisiológicas e metabólicas normais do fruto, modificando o aroma, o sabor e a coloração interna (Clark et al., 1997). Tais injúrias são acompanhadas por elevado número de respostas fisiológicas e promovem o rompimento das células da epiderme, causando o desenvolvimento de reações enzimáticas e, com isso, o surgimento de composto de coloração marrom, responsáveis pela depreciação do produto (Radi et al., 1997).

Sendo as injúrias mecânicas cumulativas nas várias etapas do manuseio, do campo ao consumidor, devem ser cuidadosamente coordenadas e integradas para minimizar as perdas na qualidade do produto.

Segundo Kader (2002), a qualidade visual responde por $83 \%$ das razões que leva os consumidores a escolherem um determinado produto, sendo enormemente afetada pela presença de defeitos. O objetivo deste trabalho foi avaliar os efeitos das injúrias mecânicas por corte, compressão e impacto na qualidade pós-colheita de pêssegos 'Aurora-1'.

\section{MATERIAL E MÉTODOS}

Foram utilizados pêssegos 'Aurora-1', produzidos no município de Taiuva-SP. Os frutos foram colhidos "de vez" nas primeiras horas da manhã, de forma inteiramente casualizada, e transportados de forma rápida e cuidadosa para o Laboratório de Tecnologia dos Produtos Agrícolas da FCAV/UNESP Jaboticabal, onde foram submetidos a criteriosa seleção, visando a dar máxima uniformidade do lote. Após esta seleção, foram imersos em solução de hipoclorito de sódio a $200 \mu \mathrm{L}$.L, por 5 minutos e deixados em repouso em ar ambiente para que o excesso de líquido escorresse e secasse.

Os tratamentos consistiram em submeter os frutos a diferentes injúrias mecânicas. No tratamento de impacto, os pêssegos foram deixados cair duas vezes de uma altura de 1,20 m sobre uma superfície maciça, plana e rígida, atingindo-os na região equatorial, em lados opostos. No tratamento de compressão, os frutos foram colocados sob um bloco exercendo um peso constante de $3 \mathrm{~kg}$ por 10 minutos. Para a injúria por corte, promoveram-se três incisões longitudinais, com $2 \mathrm{~cm}$ de comprimento, $2 \mathrm{~mm}$ de profundidade e $1,1 \mathrm{~mm}$ de espessura.
Manteve-se, ainda, um lote de pêssegos intactos, correspondente ao Controle. Após esses tratamentos, os frutos foram armazenados a $10 \pm 1,5^{\circ} \mathrm{C}$ e $85 \pm 2 \%$ UR por oito dias.

Diariamente, foram realizadas análises da aparência e da perda de massa fresca. A cada dois dias, avaliaram-se os teores de sólidos solúveis (SS), de acidez titulável (AT), a aparência, a firmeza, a coloração, e o conteúdo de carboidratos solúveis, além da relação $\mathrm{SS} / \mathrm{AT}$.

A massa fresca foi avaliada através de pesagem em uma balança eletrônica Marte, modelo AS 2000, com precisão de 0,02 g. A coloração interna foi feita nos locais injuriados e nãoinjuriados, imediatamente abaixo do epicarpo, usando-se um reflectômetro Minolta CR-200b (Minolta Corp, 1994). A firmeza da polpa foi feita usando-se penetrômetro, marca Bishop FT 327. A aparência foi determinada através de atribuição de notas aos frutos, onde: 5 (excelente) = fruto túrgido, sem podridões, exsudações, ou marcas de lesão; 4 (boa) = fruto túrgido, sem podridões e exsudações, com marcas de lesões pouco evidentes; 3 (aceitável) $=$ fruto túrgido, sem podridões e exsudações, com marcas nítidas de lesões; 2 (ruim) $=$ fruto murcho, sem podridões e exsudações, com lesões profundas; 1 (péssimo) = fruto murcho, com podridões, exsudações ou lesões profundas. A acidez titulável (AT) foi determinada com base no método da AOAC (1997). O teor de sólidos solúveis (SS) foi determinado com o auxílio de um refratômetro digital, marca Atago Palette PR-101, conforme AOAC a (1997). A relação SS/AT foi realizada segundo Tressler \& Joslyn (1961). Os carboidratos solúveis foram dosados de acordo com Faleiros (1978) e determinados pelo método fenolsulfúrico, segundo Dubois et al. (1956).

O experimento foi conduzido conforme delineamento experimental inteiramente casualizado, em esquema fatorial 4x5 (tratamentos $\mathrm{x}$ tempo). Foram utilizadas três repetições, e três pêssegos por repetição.

Os dados obtidos foram submetidos à análise de variância, pelo teste $\mathrm{F}$, e as médias comparadas mediante o teste de Tukey, em nível de 5\% de probabilidade (SAS INSTITUTE INC., 2004). A perda de massa fresca foi analisada comparandose a significância do paralelismo das retas obtidas, pelo Teste T (Neter et al., 1978).

\section{RESULTADOS E DISCUSSÃO}

Os frutos submetidos ao tratamento impacto levaram a uma maior perda de massa fresca que os frutos do controle e os submetidos à compressão e ao corte (Figura 1). Durante o período de armazenamento, o impacto resultou numa perda de massa fresca acumulada de $6 \%$, sendo esta superior aos demais tratamentos, como pode ser visualizado na Figura 1. Perdas de massa fresca também foram observadas por Chuma et al. (1984), em morangos submetidos a injúrias por impacto, durante o transporte. Verificaram que as frutas transportadas apresentaram maior perda de água que as não-submetidas ao transporte. Sanches et al. (2003) também observaram maior perda de massa fresca em abacates devido às injúrias provocadas por compressão, corte e impacto. Os frutos dos diversos tratamentos apresentaram perda de massa fresca semelhante, inclusive o 
tratamento-controle, diferindo apenas do tratamento de impacto, que, após o $3^{\circ}$ dia, apresentou a maior perda de massa fresca, devido às injúrias impostas.

$\mathrm{Na}$ Figura 2, tem-se o comportamento da aparência atribuídas aos pêssegos, nos diferentes dias de análise, sendo observado que todos os tratamentos tiveram uma perda na qualidade ao longo do armazenamento. $\mathrm{O}$ controle foi o que se apresentou mais estável, sendo que os tratamentos impacto e compressão obtiveram maior perda da aparência desejável. Durante o período de análise, observou-se também que os frutos, ao serem cortados, apresentavam escurecimento no local injuriado, o que não era evidente externamente. Durante o período de armazenamento, os frutos do tratamento-controle apresentavam-se sem degradações visíveis, o que os tornavam aptos para a comercialização. Mattiuz et al. (2002) também verificaram que o estresse físico, causado pelo impacto, produziu um colapso interno nos lóculos de goiabas (internal bruising), levando à perda da integridade celular e à conseqüente liquefação dos tecidos placentários.

Com relação à avaliação da coloração da polpa dos frutos, ao longo do armazenamento, é possível observar que houve diferenças significativas entre os tratamentos (Tabela 1). A luminosidade indica que os frutos submetidos ao impacto tornaram-se mais escuros que os dos demais tratamentos, o que também foi verificado na injúria por compressão. A luminosidade também indicou que os tratamentos obtiveram a mesma coloração no $1^{\circ}$ e $2^{\circ}$ dias, aumentando no $4^{\circ}$ dia, estabilizando, não diferindo significativamente. Em goiabas das cultivares Paluma e Pedro Sato, a área injuriada apresentou-se mais escura nos frutos submetidos às injúrias de impacto, compressão e corte (Mattiuz e Durigan, 2001). Com o provável rompimento das células, devido à magnitude da força empregada, ocorre o extravasamento do líquido celular e sua conseqüente exposição à ação enzimática, resultando em oxidação de compostos fenólicos a quinonas, o que leva ao aparecimento de pigmentos de coloração marrom (Radi et al., 1997).

Nos frutos injuriados por impacto, o ângulo de cor diferiu significativamente, apresentando uma cor amarelo-esverdeada, enquanto os demais tratamentos tiveram uma cor mais amarelada, indicando retardo no amadurecimento (Tabela 1). $\mathrm{O}$ aumento desse ângulo nas áreas injuriadas pode ter sido influenciado pela oxidação de compostos que contribuíram também para o maior escurecimento. Apesar de não diferirem significativamente, as áreas lesionadas apresentaram maiores valores para a cor que as áreas não-lesionadas, confirmando o efeito deletério da injúria. Efeito similar foi verificado por Durigan et al. (2005) quando a injúria por impacto levou limas-ácidas 'Tahiti' a maior perda na cor verde, principalmente nas regiões lesionadas. Em goiabas, Mattiuz e Durigan (2001) constatou mudanças no ângulo de cor, do verde para o amarelo, em frutos que sofreram injúrias mecânicas, ou seja, acelerando o amadurecimento daqueles frutos. As injúrias levaram a uma alteração no processo metabólico dessas regiões e, como conseqüência, a irregularidade do amadurecimento.
Dentre os tratamentos aplicados, o impacto levou à menor cromaticidade (Tabela 1), pois a saturação de pigmentos foi significativamente menor nas áreas injuriadas que nas áreas nãoinjuriadas, comprovando o seu efeito prejudicial na coloração. A firmeza foi menor nos frutos em que foram submetidos às injúrias (Tabela 1). A maior perda de firmeza foi verificada na injúria por impacto, o qual diferiu significativamente dos demais. Quando se analisa o efeito das lesões, nota-se que as áreas dos frutos submetidos às injúrias era, na média, menos firmes que as partes não-injuriadas, sendo que esse efeito foi bem mais evidente no tratamento por impacto.

$\mathrm{Na}$ Tabela 2, constata-se que os tratamentos não afetaram os teores de sólidos solúveis (SS) da polpa dos pêssegos. Houve evolução desses teores ao longo do armazenamento, o que se deve ao amadurecimento dos frutos. Giannoni et al. (1996) observaram uma maior concentração de SS em pêssegos, ao longo do armazenamento, indicando que este aumento foi devido à perda de água pelos frutos durante o armazenamento.

A acidez titulável (AT) foi menor nos frutos injuriados e diminuiu durante o período de armazenamento dos mesmos (Tabela 2). A intensidade desta redução foi afetada pela injúria imposta no fruto, tendo-se notado diferenças entre os frutos injuriados e os do controle. Houve redução nos teores de AT, durante o armazenamento, com os frutos recém-colhidos apresentando os maiores valores. A diminuição dos ácidos provavelmente ocorreu, devido ao consumo destes como substrato no processo respiratório, mormente nos frutos injuriados. Isto foi também verificado por Durigan et al. (2005) com o impacto reduzindo os teores de SS e AT e provocando aumento na produção de $\mathrm{CO}_{2}$, em limas-ácidas 'Tahiti'. Moretti et al. (1998) observaram que a injúria mecânica por impacto levou à redução na acidez titulável de tomates, o que também foi atribuída à diminuição na concentração de ácidos orgânicos.

A relação $\mathrm{SS} / \mathrm{AT}$, também denominada índice de maturação, é um importante parâmetro qualitativo, pois indica o gosto do produto, uma vez que ele é o resultado do balanceamento entre estes constituintes. Na Tabela 2, pode-se observar que esta relação não foi influenciada significativamente pelas injúrias; no entanto, nota-se que os maiores índices foram atribuídos aos pêssegos submetidos às injúrias, devido à redução nos teores de AT. Durigan (2003) verificou evolução semelhante para este parâmetro em mangas injuriadas e armazenadas sob condição de ambiente.

Os teores de carboidratos solúveis dos tratamentos injuriados não diferiram significativamente do controle (Tabela 2). Em relação ao tempo de armazenamento, os carboidratos solúveis aumentaram ao longo das avaliações. O teor de açúcares usualmente aumenta com o amadurecimento dos frutos através de processos de biossíntese ou pela degradação de polissacarídeos, levando os valores médios a aumentos são na ordem de 10\% (Chitarra \& Chitarra, 2005). 


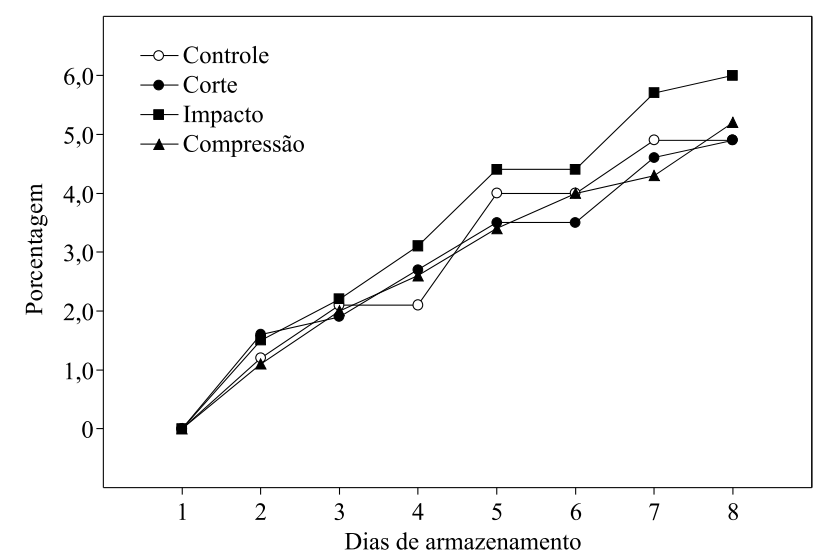

FIGURA 1 - Perda de massa fresca acumulada de pêssegos 'Aurora-1' submetidos a diferentes injúrias mecânicas e armazenados a $10^{\circ} \mathrm{C}$ e 85 \% UR por 8 dias.

TABELA 1 - Coloração interna e firmeza de pêssegos 'Aurora-1' submetidos a diferentes injúrias mecânicas e armazenados a $10^{\circ} \mathrm{C}$ e $85 \%$ UR.

\begin{tabular}{|c|c|c|c|c|}
\hline Variável & $\mathbf{L}^{*}$ & Hue* & $C^{*}$ & $\begin{array}{c}\text { Firmeza } \\
\text { (kPa) }\end{array}$ \\
\hline \multicolumn{5}{|l|}{ Tratamento } \\
\hline Controle & $74,74 \mathrm{a}$ & $102,45 \mathrm{~b}$ & $51,37 \mathrm{a}$ & $3,30 \mathrm{a}$ \\
\hline Corte & $75,27 \mathrm{a}$ & $102,19 b$ & $52,90 \mathrm{a}$ & $3,13 \mathrm{a}$ \\
\hline Impacto & $70,33 \mathrm{c}$ & $108,04 \mathrm{a}$ & $48,69 \mathrm{~b}$ & $2,79 b$ \\
\hline Compressão & $72,76 \mathrm{~b}$ & $101,41 \mathrm{~b}$ & $52,18 \mathrm{a}$ & $3,04 \mathrm{a}$ \\
\hline DMS & 1,74 & 4,46 & 1,67 & 0,30 \\
\hline \multicolumn{5}{|l|}{ Lesão } \\
\hline Área não lesionada & $74,30 \mathrm{a}$ & $102,53 \mathrm{a}$ & $51,88 \mathrm{a}$ & $3,30 \mathrm{a}$ \\
\hline Área lesionada & $72,24 \mathrm{~b}$ & $104,51 \mathrm{a}$ & $50,69 \mathrm{~b}$ & $2,82 \mathrm{~b}$ \\
\hline DMS & 0,91 & 2,37 & 0,87 & 0,16 \\
\hline \multicolumn{5}{|l|}{ Tempo } \\
\hline 0 & $75,37 \mathrm{a}$ & $105,27 \mathrm{a}$ & $52,83 \mathrm{a}$ & $3,37 \mathrm{a}$ \\
\hline 2 & $74,26 \mathrm{a}$ & $105,53 \mathrm{a}$ & $50,87 \mathrm{a}$ & $3,25 \mathrm{a}$ \\
\hline 4 & $71,91 \mathrm{~b}$ & $101,78 \mathrm{a}$ & $50,74 \mathrm{~b}$ & $3,03 \mathrm{a}$ \\
\hline 6 & $72,84 \mathrm{~b}$ & $102,86 \mathrm{a}$ & $51,07 \mathrm{a}$ & $2,74 \mathrm{~b}$ \\
\hline 8 & $72,00 \mathrm{~b}$ & $102,18 \mathrm{a}$ & $50,92 \mathrm{a}$ & $2,92 \mathrm{a}$ \\
\hline DMS & 1,81 & 7,31 & 2,06 & 0,48 \\
\hline CV (\%) & 3,06 & 8,72 & 4,97 & 19,36 \\
\hline
\end{tabular}

$\mathrm{L}=$ Luminosidade; Hue = Ângulo de cor; $\mathrm{C}=$ Cromaticidade.

Médias seguidas da mesma letra na coluna, não diferem entre si, pelo teste de Tukey, a $5 \%$ de probabilidade.

\section{CONCLUSÕES}

As injúrias mecânicas afetaram a aparência dos frutos, que obtiveram nota ruim a partir do $6^{\circ}$ dia de armazenamento. No tratamento de impacto, foram as injúrias que promoveram maiores danos à qualidade de pêsssegos 'Aurora-1', verificado pela maior perda de massa fresca, piora da coloração interna e menor firmeza dos frutos. As injúrias mecânicas promoveram amadurecimento mais rápido dos frutos.

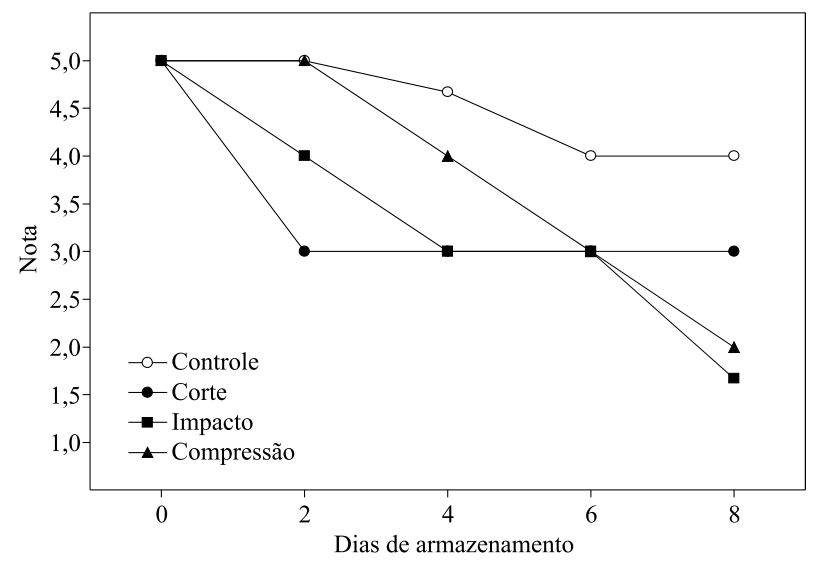

FIGURA 2 - Evolução da aparência externa de pêssegos 'Aurora1' submetidos a diferentes injúrias mecânicas e armazenados a $10{ }^{\circ} \mathrm{Ce} 85 \%$ UR. $(5=$ excelente; $4=$ bom; 3 = médio; 2 = ruim, $1=$ péssimo)

TABELA 2 - Qualidade de pêssegos 'Aurora-1' submetidos a diferentes injúrias mecânicas e armazenados a 10 ${ }^{\circ} \mathrm{Ce} 85 \%$ UR.

\begin{tabular}{lcccc}
\hline \multicolumn{1}{c}{ Variável } & SS & AT & SS/AT & CS \\
\hline Tratamento & & & & \\
$\quad$ Controle & $12,73 \mathrm{a}$ & $0,33 \mathrm{a}$ & $39,19 \mathrm{a}$ & $10,87 \mathrm{a}$ \\
Corte & $12,58 \mathrm{a}$ & $0,29 \mathrm{~b}$ & $45,57 \mathrm{a}$ & $10,83 \mathrm{a}$ \\
Impacto & $12,25 \mathrm{a}$ & $0,29 \mathrm{~b}$ & $45,44 \mathrm{a}$ & $11,22 \mathrm{a}$ \\
Compressão & $12,83 \mathrm{a}$ & $0,30 \mathrm{ab}$ & $45,88 \mathrm{a}$ & $10,77 \mathrm{a}$ \\
\hline DMS & 1,18 & 0,38 & 9,73 & 1,81 \\
\hline Tempo & & & & \\
0 & $11,40 \mathrm{c}$ & $0,43 \mathrm{a}$ & $26,56 \mathrm{~b}$ & $9,83 \mathrm{c}$ \\
2 & $12,20 \mathrm{bc}$ & $0,27 \mathrm{~b}$ & $45,51 \mathrm{a}$ & $10,65 \mathrm{abc}$ \\
4 & $12,53 \mathrm{~b}$ & $0,27 \mathrm{~b}$ & $48,01 \mathrm{a}$ & $10,56 \mathrm{bc}$ \\
6 & $13,90 \mathrm{a}$ & $0,29 \mathrm{~b}$ & $49,88 \mathrm{a}$ & $12,06 \mathrm{a}$ \\
8 & $12,96 \mathrm{~b}$ & $0,26 \mathrm{~b}$ & $50,13 \mathrm{a}$ & $11,52 \mathrm{ab}$ \\
\hline DMS & 0,94 & 0,49 & 11,05 & 1,48 \\
\hline CV $(\%)$ & 6,34 & 13,69 & 21,29 & 11,48 \\
\hline
\end{tabular}

$\mathrm{SS}=$ sólidos solúveis $\left({ }^{\circ}\right.$ Brix $)$; $\mathrm{AT}=$ acidez titulável $\left(\mathrm{g}\right.$ ácido cítrico $\left.100 \mathrm{~mL}^{-1}\right)$; $\mathrm{CS}=$ carboidratos solúveis $\left(\mathrm{g}\right.$ de glicose $\left.100 \mathrm{~m} \mathrm{~L}^{-1}\right)$.

Médias seguidas da mesma letra comun, na coluna, não diferem entre si, pelo teste de Tukey, a $5 \%$ de probabilidade.

\section{AGRADECIMENTOS}

Os autores agradecem à FAPESP pelo auxílio financeiro (Proc. n. 03/08592-2).

\section{REFERÊNCIAS}

AGRIANUAL: anuário da agricultura brasileira. 2006. 11. ed. São Paulo:FNP, 2006. 504p. 
AOAC. Official methods of analysis of the Association of Analytical Chemists. 13 ${ }^{\text {th }}$ ed. Washington: AOAC, 1997. $1018 p$.

CHITARRA, M.I.F.; CARVALHO, V.D. Qualidade e industrialização de frutos temperados: pêssegos, ameixas e figos. Informe Agropecuário, Belo Horizonte, v.11, n.125, p.56-66, 1985.

CHITARRA, M.I.F.; CHITARRA, A.B. Pós-colheita de frutos e hortaliças: fisiologia e manuseio. Lavras: ESAL-FAEPE, 2005. $785 \mathrm{p}$.

CHUMA, Y.; MURATA, S.; IWAMOTO, M.; NISHIHARA, A.; HORI, Y. Donner strawberry transportation in refrigerated truck for 700 kilometers. Annals of the Agricultural Engineering Society, v. 45, n. 2, p. 292-297, 1984.

CLARK, C. J.; HOCKINGS, P. D.; JOYCE, D. C.; MAZUCCO, R. A. Application of magnetic resonance imaging to pre- and post-harvest studies of fruits and vegetables. Postharvest Biology and Technology, Amsterdan, 11, p. 1-21, 1997.

DUBOIS, M.; GILLES, K.A.; HAMILTON, J.K.; REBER, P.A.; SMITH, F. Colorimetric method for determination of sugars and related substances. Analytical Chemistry, Washington, v.8, n.3, p.350-356, 1956.

DURIGAN, M.F.B. Injúrias mecânicas na qualidade de mangas 'Palmer' e 'Keitt'. 2003. 63f. Monografia (Trabalho de Graduação em Agronomia) - Faculdade de Ciências Agrárias e Veterinárias, Universidade Estadual Paulista, Jaboticabal, 2003.

DURIGAN, M.F.B.; MATTIUZ, B.H.; DURIGAN, J.F. Efeito de injúrias mecânicas na qualidade pós-colheita de lima ácida 'Tahiti'. Revista Brasileira de Fruticultura, Jaboticabal, v.27, n.3, p.369-372, 2005.

FALEIROS, R.R.S. Técnicas e experimentos de aulas práticas em bioquímica. Jaboticabal: Faculdade de Ciências Agrárias e Veterinárias, 1978. p.1-6. Apostila.

GIANNONI, J.A.; LIMA, L.C.; CHITARRA, M.I.F.; VILAS BOAS, E.V. Armazenamento de pêssegos 'Premier' sob refrigeração e atmosfera modificada. In: CONGRESSO BRASILEIRO DE FRUTICULTURA, 14., 1996, Curitiba. Resumos... Londrina: SBF, 1996. p.380.

KADER, A.A. Postharvest technology of horticultural crops. Oakland: University of California, Agriculture and Natural Resources, 2002.535p.

MATTIUZ, B.H.; DURIGAN, J.F. Efeito de injúrias mecânicas na firmeza e coloração de goiabas das cultivares Paluma e Pedro Sato. Revista Brasileira de Fruticultura, Jaboticabal, v. 23, n. 2, p. 277-281, 2001.

MATTIUZ, B.H.; BISCEGLI, C.A.; DURIGAN, J.F. Aplicações da tomografia de ressonância magnética nuclear como método não-destrutivo para avaliar os efeitos de injúrias mecânicas em goiabas 'Paluma' e 'Pedro Sato'. Revista Brasileira de Fruticultura, Jaboticabal, v.24, n.3, p.641-643, 2002.

MINOLTA CORP. Precise color communication: color control from feeling to instrumentation. Ramsey: Minolta Corporation Instrument Systems Division, 1994. 49p.

MORETTI, C.L.; SARGENT, S.A.; HUBER, D.J.; CALBO, A.G.;
PUSCHMANN, R. Chemical composition and physical properties of pericarp, locule, and placental tissues of tomatoes with internal bruising. Journal of the American Society for Horticultural Science, Alexandria, v. 123, n. 4, p. 656-660. 1998.

NETER, J.; WASSERMAN, W.; WHITMORE, G.A. Applied linear statistical models. Massachussets: Allyn and Bacon, 1978. $745 \mathrm{p}$.

OJIMA, M.; CAMPO DALL'ORTO, F.A.; BARBOSA, W.; MARTINS, F.P.; SANTOS, R.R. dos; RIGITANO, O. 'Aurora1' e 'Aurora-2': novas cultivares de pêssego doce de polpa amarela. In: CONGRESSO BRASILEIRO DE FRUTICULTURA, 10., 1989, Fortaleza. Anais... Fortaleza: SBF, 1989. p.422-425.

PEREIRA, F.M.; NACHTIGAL, J.C.; ROBERTO, S.R. Tecnologia para a cultura do pessegueiro em regiões tropicais $\mathrm{e}$ subtropicais. Jaboticabal: FUNEP, 2002. 62 p.

RADI, M.; MAHROUZ, M., JAQUAD, A. Phenolic composition, browning susceptibility, and carotenoid content of several apricot cultivars at maturity. HortScience, Alexandria, v.32, n.6, p. 1087-1091. 1997.

SANCHES, J.; DURIGAN, M.F.; DURIGAN, J.F. Efeito de injúrias mecânicas, na pós-colheita, em abacates 'Geada'. In: CONGRESSOBRASILEIRODEENGENHARIAAGRÍCOLA, 32, 2003. Anais... Goiânia: SBEA. 2003. CD-Rom.

SAS INSTITUTE INC. SAS System for Microsoft Windows: release 9.1.3, Cary, 2004.

TRESSLER, D.L.; JOSLYN, M.A. Fruits and vegetables juiceprocessing technology. Westport: The AVI Publications, 1961. $1028 \mathrm{p}$. 